\title{
Italy-Japan Workshop: a history of bilateral cooperation pushing the boundaries of robotics
}

Gabriele Trovato $^{1 * \#}$, Leonardo Ricotti ${ }^{2,3 \#}$, Cecilia Laschi ${ }^{2,3,4}$, Massimiliano Zecca $^{5}$, Sarah Cosentino $^{6}$, Luca Bartolomeo ${ }^{7,9}$, Shuji Hashimoto ${ }^{8}$, Atsuo Takanishi ${ }^{9}$, Paolo Dario $^{2,3}$

1 - School of International Liberal Studies, Waseda University, Tokyo, Japan 2 - The BioRobotics Institute, Scuola Superiore Sant'Anna, Pisa, Italy

3 - Department of Excellence in Robotics \& AI, Scuola Superiore Sant'Anna, Pisa, Italy 4 - National University of Singapore

5 - School of Mechanical, Electrical and Manufacturing Engineering, Loughborough University, UK 6 - Global Center for Science and Engineering, Waseda University, Tokyo, Japan 7 - STMicroelectronics, Schaumburg, USA

8 - Department of Applied Physics, Waseda University, Tokyo, Japan 9 - Department of Mechanical Engineering, Waseda University, Tokyo, Japan

$$
\begin{gathered}
\text { * Corresponding author, } \\
\text { e-mail: gabriele@takanishi.mech.waseda.ac.jp } \\
\#=\text { authors equally contributing to this work }
\end{gathered}
$$

\begin{abstract}
This paper presents the experience of a long-lasting collaboration in robotics between the countries of Japan and Italy. The diversity of the approaches to robotics research and technology in the two countries and, at the same time, the similarity of some social drives for robotics progress have created a stimulus to the generation of new thinking about robotics. Not only at the main participant institutions of Waseda University in Tokyo and Scuola Superiore Sant'Anna in Pisa, but also worldwide. The authors present a summary of the Italy-Japan Workshops exploring topics on a) humanoid robotics, b) application of robotics for exploration and rescue, c) biorobotics, d) the use of robots in education, e) the ethics of robotics, f) robotics for sport and g) robotics in arts. The experience of the Workshops represents an example of an open-minded approach to robotics, grounded on social challenges, explored through multidisciplinary discussions, faced by interdisciplinary research, overall interesting to share with the international robotics community. This
\end{abstract}


approach could be used as a base model to foster further international collaborations between different countries as well.

\section{Keywords:}

Research trends, humanoids, biorobotics, robotics, ethics, medical robotics, exploration, education 


\section{Introduction}

Italy and Japan are two countries with a long tradition in the design and production of robots, which traces back to Leonardo da Vinci's automata in the Renaissance [1] and to Karakuri puppets used in Shinto festivals and in tea ceremonies since the $14^{\text {th }}$ Century [2].

As leading countries in this field, both have been widely applying robots in their industrial production, especially in the automotive sector (Figure 1a). In the automation of industrial production, they figure in the top ten countries with the highest installed number of multipurpose industrial robot units. In robotics research, both Japanese and Italian scientists are well represented in the international community and their scientific production has been traditionally considerable, counting together $15 \%$ of the world publications production.
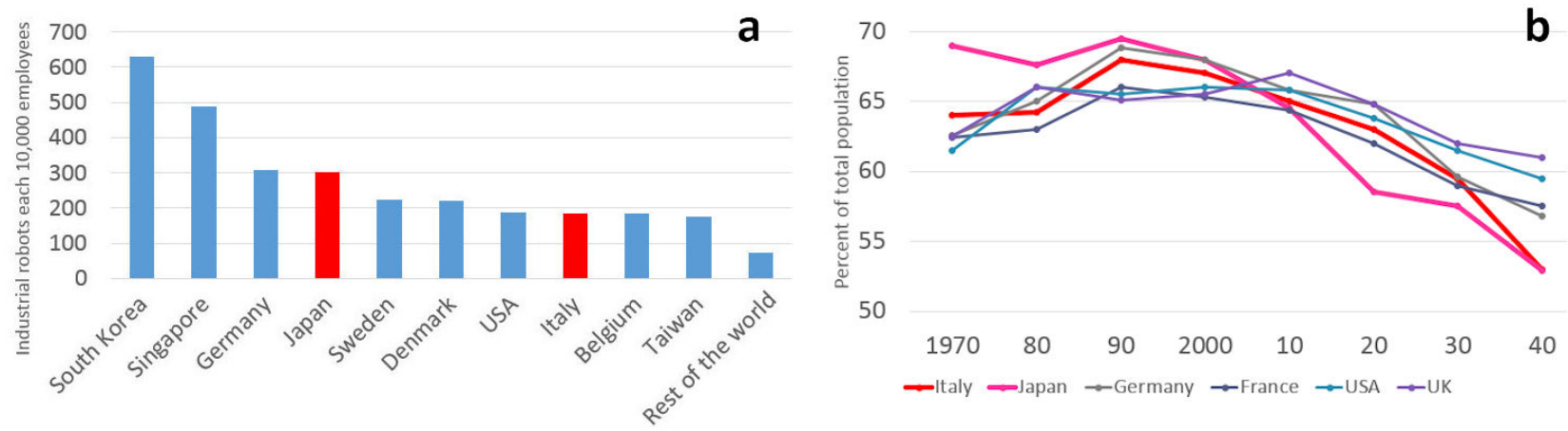

Figure 1: (a) Countries with the highest density of Robot workers (source: IFR); (b) Working-age population percent, including forecast, according to United Nations Prospect 2017.

Similarities in social and geographical challenges are also present. For instance, both countries have a sub-replacement fertility rate, with the TFR (Total Fertility Rate) of Italy at 1.46 and Japan 1.44 [3]. In both countries, the population over 65 years represents around one-quarter of the total $(27 \%$ in Japan and 23\% in Italy), making them the fastest ageing countries in the world [3][4], and causing a shrinking percentage of the working-age population (Figure 1b). According to the Ministry of Health, Labour and Welfare of Japan, there are over 30,000 nursery homes spread across the territory, and an even higher number of daycare facilities. In this context of ageing societies, there is a growing need for socially assistive devices, which have a potential market of 30 million users only in Japan, and for workforce provided by robotics. Similarly, on the geographical aspect, the volcanic nature of the lands and the strong dependence on marine resources, make the territories of both countries very fragile ecosystems, exposed to earthquakes and extremely sensitive to climate change-related issues.

Moreover, Italy and Japan share a deep passion for art, close attention to design and strong desire for innovation. At the same time, the approach to these disciplines is very different, given the cultural 
diversity, the distant traditions, the profound difference in religious attitude and the contrasting citizens' perception of technology. Robotics is an interdisciplinary field in which we can find interesting focal points for scientific discussion and mutual growth in the field.

This combination of similarity of interests and differences in the approaches brought to the ItalyJapan Workshops, a series of events organised by the Italian Embassy in Tokyo, with the scientific support of Scuola Superiore Sant'Anna (Pisa, Italy) and Waseda University (Tokyo, Japan), since 2001. It also led to the creation of two joint laboratories on humanoid and personal robotics, partially supported by the Italian Ministry of Foreign Affairs: RoboCasa, which opened in Tokyo (Japan) in 2003, and Robot-An, which opened in Pontedera (Pisa, Italy) in 2007. The two names are connected by a similar meaning: Casa meaning "home" in Italian and An (庵) meaning "hermitage" in Japanese. These two joint labs were a key part of a larger strategic objective, namely the creation and strengthening of a reliable link between Japan and Italy, by connecting universities, research centres, and small and middle enterprises in the two nations (and, as a natural extension, in Europe and Asia) in the fields of advanced robotics, medical and biomedical technologies and related biomechatronic technologies (Figure 2a). This approach has been pursued at three different levels: excellence in research, joint education and strengthening of industrial relationships.

Year by year, each Workshop became not only an event of considerable scientific level, but also a reference point between the Italian and Japanese robotics communities, providing stimulus to the generation of new thinking about robotics. Additionally, the collaboration in the field of robotics, between the two countries, brought to the first Doctoral Summer School in Robotics in 2009, including eventually South Korea. 


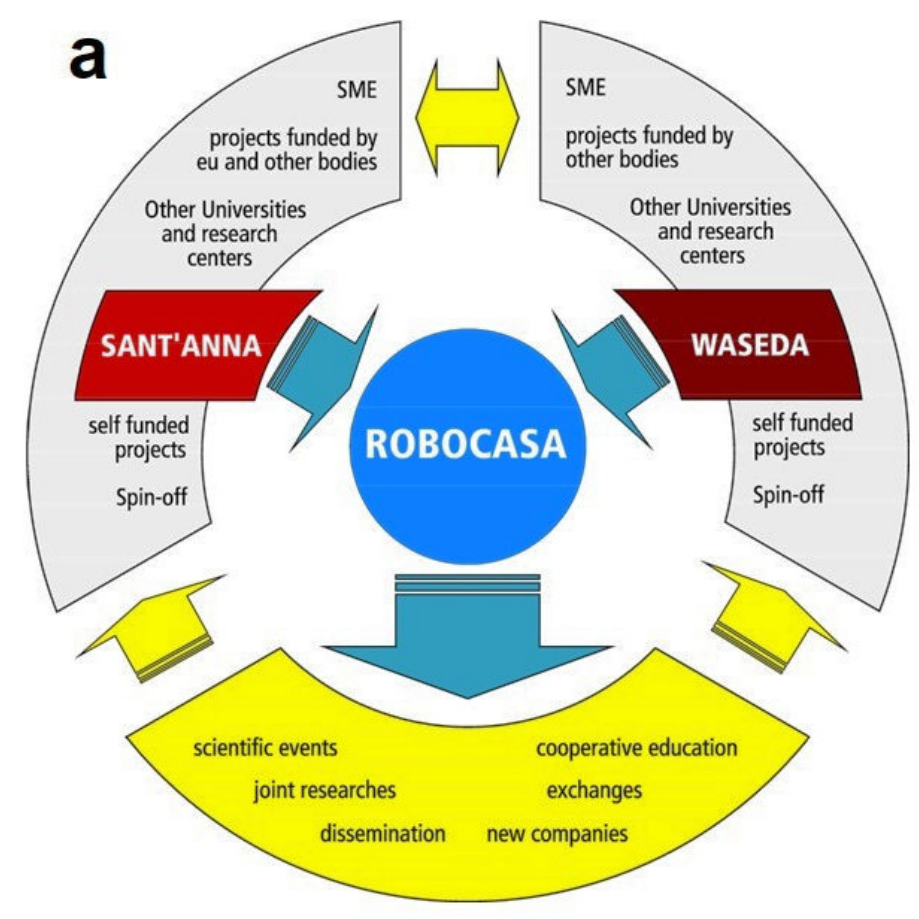

\begin{tabular}{l|l}
\hline 2001 & Humanoids, a Techno-ontological approach \\
\hline 2003 & Research on Humanoid, Service and Rescue Robots in Italy and in Japan \\
\hline 2005 & The man and the robot: Italian and Japanese approaches \\
\hline 2006 & Robots and humans \\
\hline 2007 & Robots are already among us! \\
\hline 2009 & Service robotics - Medical robotics \\
\hline 2010 & Robotics and Education in Italy and Japan \\
\hline 2011 & New critical challenges in Robotics \\
\hline 2012 & Assistance robots for disasters \\
\hline 2013 & Technologies for humans and humanoid robotics \\
\hline 2014 & Robot co-worker - towards a society supported by robot co-workers \\
\hline 2015 & Can robots save the world economy? \\
\hline 2016 & Robotics and the Arts \\
\hline 2017 & Robotics and Sport science \\
\hline 2018 & The first robots - Leonardo Da Vinci and the history and future of mechanisms \\
\hline 2019 & Robots and the future \\
\hline
\end{tabular}
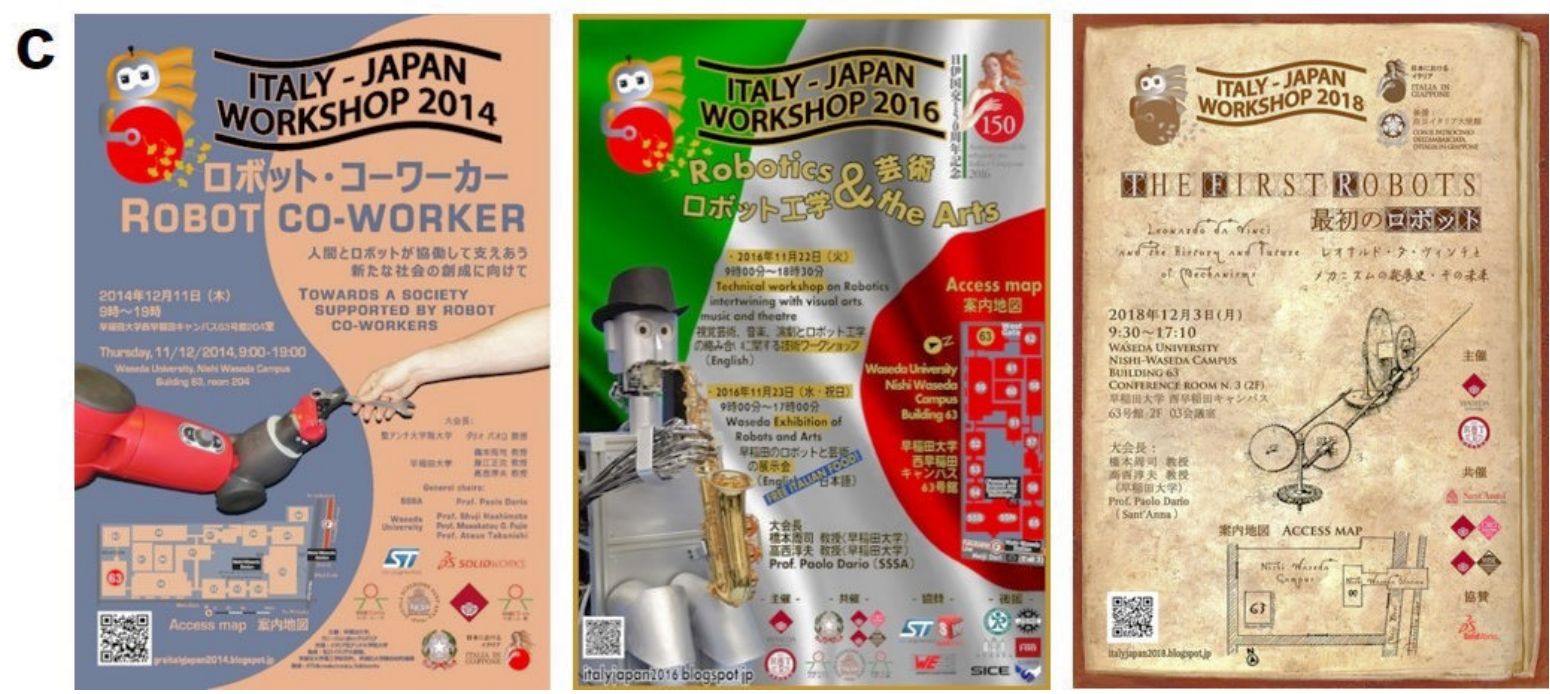
Figure 2: (a) The RoboCasa model of cooperation between Italy and Japan; (b) List of the ItalyJapan Workshops on robotics and their titles; (c) examples of advertising material for the Workshop (from left to right: editions of 2014, 2016 and 2018).

The Italy-Japan Workshops can be considered excellent monitoring centres of the evolutions in the interdisciplinary research efforts related to robotics in these two countries and beyond their borders.

This paper aims at describing the evolution of robotics research in Italy, Japan and beyond in the last two decades, mapped through the themes (Figure 2b/c) touched by the Workshops: a) Humanoid robotics, b) Robots for rescue, exploration and to face natural disasters, c) Biorobotics, d) Robotics and Education, e) Ethical, social, legal and economic aspects of robotics, f) Robotics for sport and g) Robotics for arts.

\section{Humanoid robotics}

Humanoid robotics constituted the main focus of the first decade of the Italy-Japan collaboration, as well as the theme of the first Italy-Japan Workshop edition, held at Waseda University in 2001, entitled "Humanoids: A Techno-Ontological Approach".

Waseda University has always been at the frontier of the research on humanoids, since Prof. Ichiro Kato and his colleagues began developing artificial prostheses in 1967, then it went one step further starting the ambitious WABOT Project in 1970, leading to the development of WABOT-1 in 1973 and WABOT-2 in 1984 [5].

The target of Kato's efforts was indeed to develop robots having in mind a 20 30 years horizon. In the ' $70 \mathrm{~s}$, it had been forecast that robots would penetrate society in the $21^{\text {st }}$ century not only in secondary industry but also in the service industry, substituting human labourers. For that reason, it was assumed that robots would be required to have anthropomorphic appearance and abilities, to move in and deal with an environment tailored to standard-able humans. This was a very relevant societal issue at that time, when the international disability rights movement was gathering momentum and pushed to secure equal opportunities for people with disabilities, demanding a more sociologically inclusive design, promoting new standards for accessibility and safety in architecture, transportation, and the physical environment.

In the following decades, the Humanoid Project began and a variety of humanoid robots were developed, including Hadaly-1 in 1995, and Hadaly-2 and WABIAN in 1997 [6]. This project led to the formal establishment of the Humanoid Robotics Institute in 2000. In the same year, the IEEERAS International Conference on Humanoid Robots was established, and Honda [7] announced the development of ASIMO. 
In the same period, in Italy, and more in general in the western countries, researchers were focusing on improving the acceptance of humanoid robots through advanced design, to facilitate their coexistence with humans [8]. This was a major issue for humanoid robotics research in Italy, where the very name "humanoid" was stigmatised. The difference of attitude and the citizens' perception about humanoid robotics gave a strong impetus to shape the first Italy-Japan Workshop on both technological and social aspects of this research field, which were deeply analysed and discussed in an enlarged event not limited to roboticists but including philosophers, theologians, and sociologists. Here, the speakers introduced discussions on artificial consciousness, robot mind and intelligence, anthropomorphisms and social acceptability, perception and sensorimotor coordination: all topics that would have become central in the following years until present days, in which the concrete capabilities of artificial intelligence (AI) are radically different from those available in 2001.

As a direct consequence of this initial event, the Embassy of Japan in Italy organised in June 2003 the event "Robots of Japan" in Rome, at the local Japanese Cultural Institute, which was stimulated by the activities of RoboCasa in Japan. The topic of humanoid robotics and the differences in robotics in the two countries were discussed again in the 2003 Workshop.

In 2005, the Workshop was entitled "The Man and The Robot: Italian and Japanese Approaches". Here, the theme was centred not only on recent evolutions of robots, but also on how these advancements were perceived by Italian and Japanese people, highlighting the paradigmatic differences. In Italy, or more generically in Western culture, there is general skepticism towards technologies aimed at substituting humans or going in close contact with them and is affected by the so-called Frankenstein complex, namely the fear of man-made creatures who may go out of control. Italy is specifically involved in such a complex, being home of the novel of Pinocchio. Conversely, in Japan, this complex seems to be absent and robots are culturally seen as heroes who may save mankind. One example of this acceptance was clearly shown in the event Robodex 2003. As part of the event, the Waseda's WE-4R emotional humanoid robot provided with the SSSA RCH-1 artificial hand [9] was exhibited in front of a vast crowd (Figure 3a).

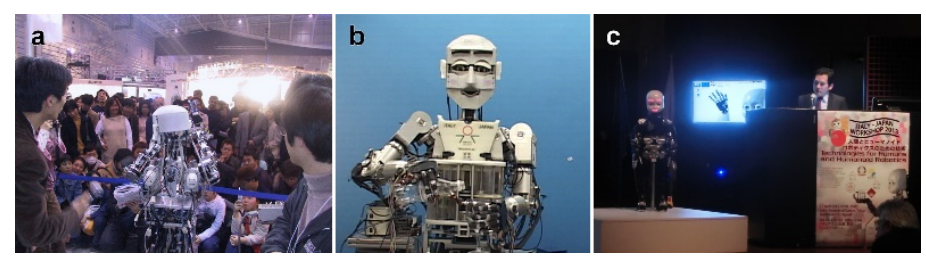

Figure 3: Images of representative milestones in the field of humanoid robotics, driven by Japanese and Italian researchers. (a) Waseda's WE-4R emotional humanoid robot with Scuola Superiore Sant'Anna's RCH-1 artificial hand exhibited at Robodex 2003; (b) the humanoid robot WE-4RII 
(Waseda Eye No.4 Refined II) with the robotic hand RCH-1 integrated; (c) iCub robot presented at the 2013 Workshop.

Takanishi [10] discussed the origins of high social acceptability of robots in Japan, tracing back to religious and social background, and connecting the high degree of anthropomorphism in Japan to the humanisation of nature present in the Edo era and tracing back to scrolls of the $12^{\text {th }}$ Century. This came approximately at the same time as [11], one of the first publications that handled the issue of cultural difference in robotics. The whole field of culturally-aware robotics begun and established its importance [12] within social robotics through the years. The European Union and Japan jointly assigned 8 million euros to the winning project of the Horizon 2020 programme, called e-ViTA (EUJapan Virtual Coach for Smart Ageing), which is starting in 2021 and features several Italian institutions in the consortium. e-ViTA will place particular effort in the realisation of coaching devices that are tailored for the specific cultural and even religious [13] background of the end-users, including the development of prototypes thought for Japanese users [14] as well as users from Catholic countries such as Italy [15].

The 2005 Workshop was centred explicitly on how advancements in robotics can be perceived by Italian and Japanese people, and the idea of RobotCub was presented: an open platform available to worldwide researchers with the goal of studying cognitive manipulation skills. More than 10 years later, the humanoid iCub [16] has been adopted by more than 20 laboratories worldwide and is part of the EU project RobotCub.

The 2006 edition paved the way for the even more significant event of 2007, where a round table entitled "Educating humans and robots to co-exist" was held, which involved industrial robots in the discussion. This anticipated by a few years significant concerns about safety in dense human-robot co-existing scenarios, later leading to the standardisation in ISO 10218-1/2 of safety factors for industrial robots in 2011 [17]. Around the same time, Waseda University and Scuola Superiore Sant'Anna were integrating the robotic hand RCH-1 into the 59 DoF humanoid platform WE-4RII [18], capable of grasping a glass and a bottle of water, and pouring it, as early as 2004 (Figure 3b).

In the following years, humanoid robotics evolved through all aspects. The iCub was renovated through a new mechatronics design, a neural network interface, tactile sensors, teleoperation, affordances and skills learning, among others [19]. It was displayed in Japan in the 2013 Workshop entitled "Technologies for Humans and Humanoid Robotics" (Figure 3c).

Many intuitions that emerged from these Workshops became a reality. Exciting advancements have been made in the field of humanoid robotics research worldwide, especially concerning bipedal locomotion, dexterous manipulation and perception in complex environments. These recently led, for example, to the impressive performance of the Atlas robot by Boston Dynamics. In Italy and Japan, 
research grew thanks to the collaboration that opened towards neuroscience with the FP7-ICT RoboSoM (A Robotic Sense of Movement) project, which aimed to find new approaches to the design and development of humanoid robots with advanced human-like perception and action capabilities.

\section{Robots for rescue, exploration and to face natural disasters}

Rescue, exploration and disaster-related applications constitute an important domain of robotics in the future. In these situations, a variety of tasks can be assigned to a robot, such as inspection, surveillance, mapping, recovery from failures. On top of that, the tasks are carried out in extreme environments, such as operations underwater, on unstructured terrains, in radioactive environments, or in extremely confined systems (such as pipes), which can be extremely dangerous for human beings. One of the first examples of these applications is the Japanese snake-like robot ACM-R5H, based on the first snake-robot prototype created in 1972 [20] and now developed by the company HiBot, which features one Italian and one Japanese researcher, among its founding members.

In 2003, the Italy-Japan Workshop had the title "Research on Humanoid, Service and Rescue Robots in Italy and in Japan". A few years later, the earthquakes that stroke L'Aquila in Italy in 2009 and the north-east of Japan in 2011 accelerated the need for rescue robots. Despite the existence of research on rescue robots before that date [21], Fukushima became a proving ground for any advanced robot technologies designed to operate in hazardous conditions.

At the same time, Italy had to face the issue of monitoring water around the shipwreck of Costa Concordia, following the accident of 2012. In these regards, the Italy-Japan Workshop was centred on "New Critical Challenges in Robotics" (in 2011) and on "Assistance robots for disasters" (in 2012). In the 2012 edition, the Workshop featured the special participation of a speaker from the Tokyo Fire Department, in order to focus the needs in robotic technology in case of this kind of disaster. A relevant example of the advancements in this field was provided by the field report of rescue activity in Mirandola, Italy [22], which featured a joint force of humans with field robots, drones and $3 \mathrm{D}$ reconstruction techniques.

The discussion preceded the institution of the DARPA Robotics Challenge (DRC), launched in 2012, aiming at developing semi-autonomous ground robots able to perform complex tasks in dangerous, degraded, human-engineered environments [23].

The beginning of the "Impulsing Paradigm Change through Disruptive Technology Program" (ImPACT) initiated by the Japan Science and Technology agency (JST), and its Tough Robotics Challenge, also led to the development of WAREC-1 [24] in Waseda University, a robot capable of both crawling and walking. Recent research efforts in Italy highlighted the possibility to use a robot 
(the WALK-MAN) acting as an alter ego of the human operator, through which the subject teleoperates the robot in environments affected by natural or artificial disasters [25].

\section{Biorobotics}

Biorobotics is a highly interdisciplinary domain. Its first definitions, in the mid ' 90 s, focused on the challenges of modeling and simulating biological systems in order to provide a better understanding of human physiology [26]. Biorobotics evolved in the following decades assuming a broader connotation, including aspects related to medical robotics, but also to bioinspired robotics, thus embracing both bio-applied and bio-inspired technologies.

In 2009 the Italy-Japan Workshop had medical robotics as the central theme. The Workshop thus focused on machines used for advanced diagnosis, preoperative planning, perioperative and postoperative care, hospital logistics and scheduling, and long-term follow-up and quality control [27]. Such interests anticipated important trends of the following years, such as robotic platforms for endoscopic capsules in the gastrointestinal tract [28], minimally invasive surgery [29] (Figure 4a) and fetal surgery [30]. The Workshop also highlighted the need of developing robots by taking into account the patient's feature, in a "personalised medicine" context.
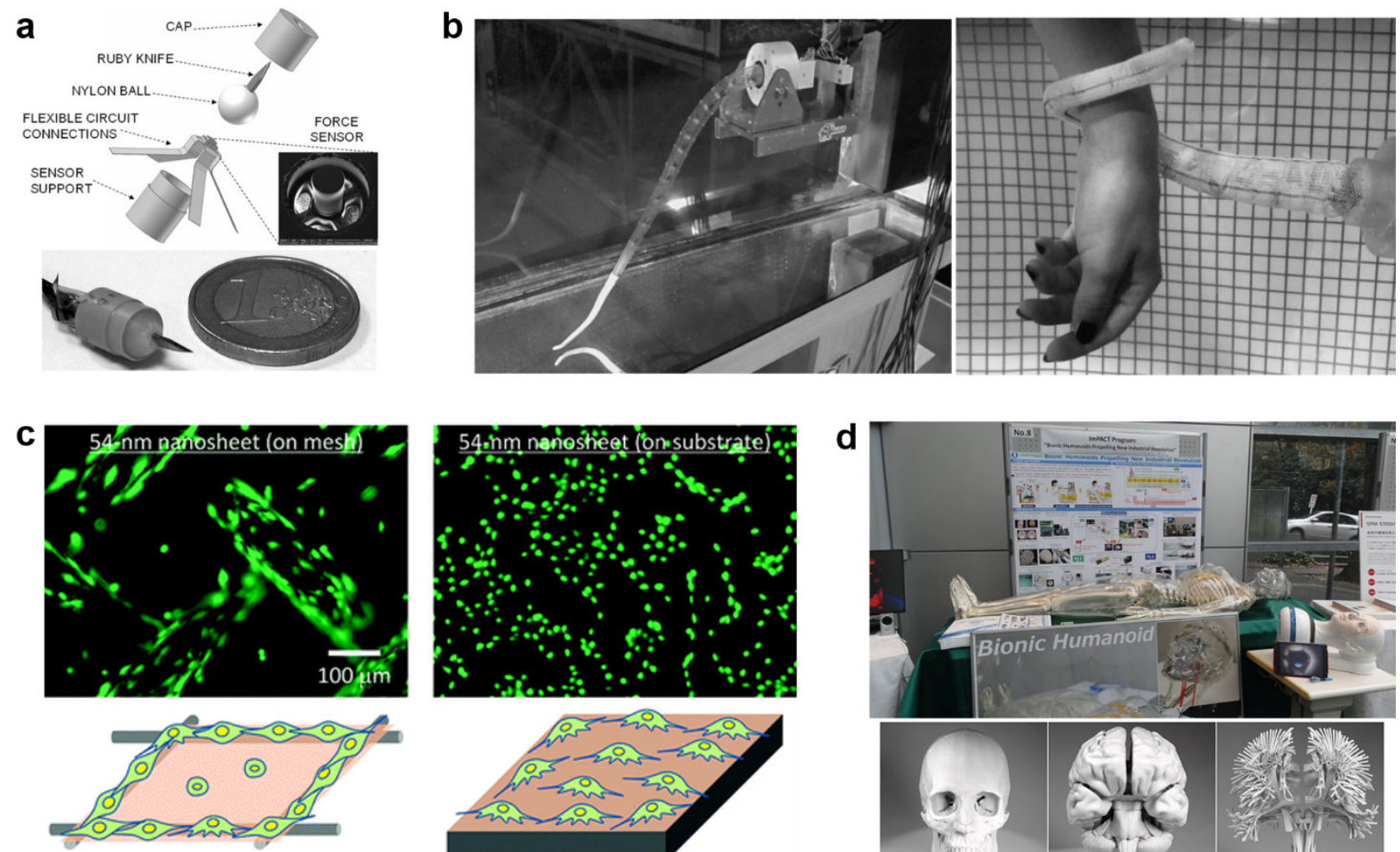

Anisotropic
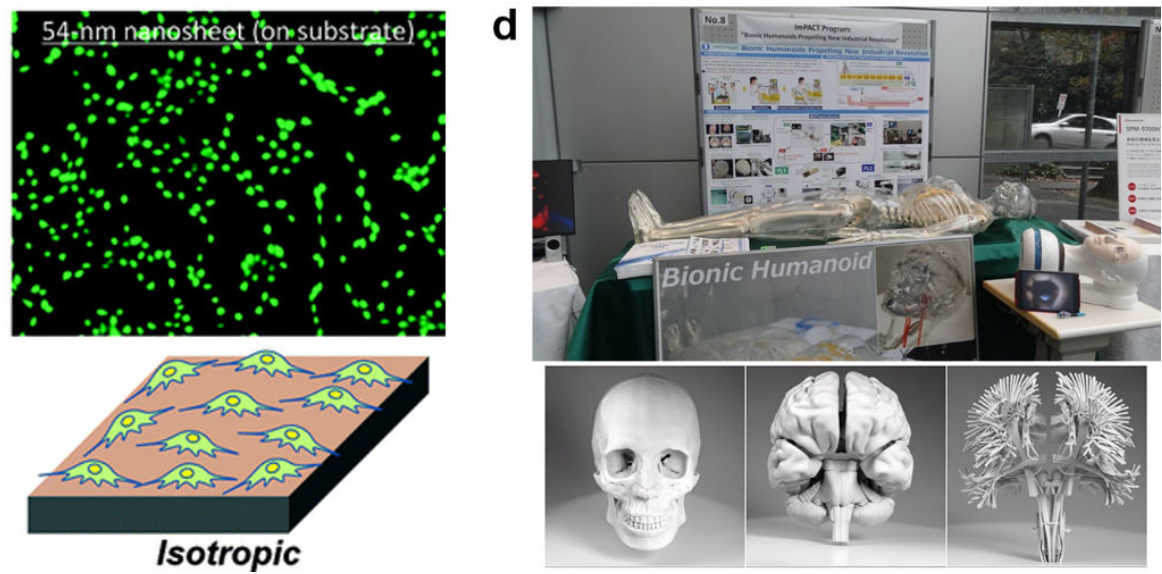
Figure 4: Examples of progresses in the fields of medical robotics and bioinspired/soft robotics, pursued by Italian and Japanese researchers: (a) miniaturised triaxial force sensor integrated in a tool for minimally invasive surgery; (b) prototype of an octopus arm-inspired robot at rest (left) and wrapping a human hand (right); (c) polymeric nanofilms used as platforms for supporting cell growth; (d) representative pictures of the "Bionic Humanoid" Japanese project.

In 2011, the Workshop addressed "New critical challenges in robotics" and highlighted the importance of emerging paradigms in biorobotics, such as bioinspired approaches to robot design and soft robotics, for the progress of robotics in the following decade. Deeply grounded in bioinspiration, soft robotics is the use of soft materials or deformable structures in robotics, so as to exploit compliance and achieve further robot abilities [31]. Beyond the first bioinspired soft robots, like the octopus-inspired arm developed at Scuola Superiore Sant'Anna (see Figure 5b), soft robotics constitutes now an extremely productive research field, worldwide [32].

In turn, this also had an effect in the field of medical tools. At the time of the 2011 Workshop, most surgical instruments were rigid, lacked a sufficient number of degrees of freedom (DOFs), and/or were incapable of modifying their mechanical properties based on the tasks to be performed. Since 2013, soft, stiffness-controllable instruments with many DOFs or even continuum kinematics appeared on the stage [33]. The number of medical robots based on a soft paradigm is continuously increasing [34] and this trend looks promising.

Newer and miniaturised enabling technologies are also paving the way toward the next generation of surgical robots. Microrobots promise enhanced diagnostic and therapeutic capabilities as well as potentially unlimited intracorporeal navigation and they are starting to seriously approach possible clinical translations. In particular, the fields of microrobotics for lab-on-a-chip applications and biohybrid robotics have seen, respectively, Japanese [35] and Italian researchers [36] at the forefront: it is worth mentioning a fruitful collaboration between Scuola Superiore Sant'Anna, the Italian Institute of Technology, Waseda University, and the Tokyo Institute of Technology, on the design and fabrication of polymeric nanofilms used as therapeutic patches or cell carriers [37] (Figure 4c) and even as components of biohybrid robots [38].

The previously mentioned 2013 Workshop, "Technologies for Humans and Humanoid Robotics", also highlighted that Italian and Japanese societies are both featured by a high life expectancy and by an increasing ageing. Both countries have been largely active in the field of artificial/bionic organs, developed to substitute heart and valves (Prof. Umezu's group) [39], pancreas (Prof. Cobelli's and Prof. Dario's groups) [40], kidney (Prof. Catapano's group) [41] and other tissues and organs. The Workshop also highlighted the potential of such technologies as components as advanced humanoid robots. Coherently with this paradigm, the Japanese government recently funded the "Bionic 
Humanoid" project (Figure 4c) [42], aimed at developing an elaborated human model equipped with sensors to serve as a substitute for trials on animals and even humans.

\section{Robotics and education}

An important application of robotics concerns education. The use of educational robots has been actually proven effective in several studies throughout the world [43],[44]. Robots can be useful not only in education programs concerning engineering, but also in language [45], history and ancient cultures [46], as well as other contexts. The topic of 'edutainment' [47] was discussed in the 2006 Workshop.

In the 2010 Workshop, completely revolving around the role of robotics in education, several initiatives and methodologies were discussed. The robotic competitions held in the University of Catania, and the 'Local Educational Laboratory on Robotics', a successful platform in Tuscany for the development of scientific and technological knowledge in schools, were presented. However, the discussion also touched issues such as the lack of official subjects related to technology or engineering in elementary schools and the introduction of control engineering studies in Japanese junior high schools, which involved building small robots and useful daily use gadgets, while raising new issues due to the unpreparedness of school teachers.

The raising problem of education to robotics was tackled during the same years in both countries. Waseda University instituted the Global Robot Academia within the Global COE (Center of Excellence) program for graduate schools, which was launched by the Japanese Ministry of Education, Culture, Sports, Science and Technology (MEXT), to establish international education and research centres. Waseda University and Scuola Superiore Sant'Anna, together with KIST, in South Korea, made a shared effort organising the WSK-TNg International Summer School on Robotics cycle, which lasted 5 years and grew to involve many other institutions.

\section{Ethical, social, legal and economic aspects of robotics}

A major outcome of the first edition of the Workshop (2001) was the discussion about techno-ethics and the so-called robo-ethics [50],[51] that afterwards was solidly brought inside the robotics community, at ICRA and IROS conferences. The word 'robo-ethics' was in fact officially used for the first time in 2004, in the First International Symposium on Roboethics, located in Sanremo, Italy. After that, a Technical Committee (TC) on Roboethics was created in IEEE-RAS in 2004. It was 
defined in this way: "Roboethics is an applied ethics whose objective is to develop scientific/cultural/technical tools that can be shared by different social groups and beliefs. These tools aim to promote and encourage the development of robotics for the advancement of human society and individuals, and to help preventing its misuse against humankind". It was classified in three levels: (1) Roboethics - intrisically referred to philosophical issues, humanities, and social sciences; (2) Robot Ethics - referring to science and technology; (3) Robot's Ethics - concerning mainly science fiction.

The European Commission then funded collaborative projects on this topic, involving roboticists and social scientists, like the ETHICBOTS, while an important outcome in Japan was the Fukuoka World Robot Declaration [52]. Several Workshops on this theme have also been organised at major robotics conferences (a few examples: ICRA in 2005, 2007 and 2009 and BioRob in 2006).

Robots as possible co-workers helping humans in boring and/or heavy works were analysed during the 2014 edition of Italy-Japan Workshop, entitled "Robot co-worker - Towards a society supported by robot co-workers". In this event, several examples of applications were discussed: agricultural, manufacturing, underwater and aerial, among others. The co-worker idea was also analysed from the viewpoint of legislative and social implications. DustCart, developed by Sant'Anna within the DustBot project and displayed in Tokyo and Osaka during the 2009 Italy-Japan Workshop edition (Figure 5) was an example of service robot [53] that had to face the legislative issue of dealing with traffic rules. The European Union faced legislation issues concerning robotics through the FP7 project RoboLaw, led by Scuola Superiore Sant'Anna in Italy [54], which was completed in the same year. Such a project had a follow-up in Japan, where the ROBOLAW.ASIA was born in Tohoku University. This research field incepted the guidelines on Ethically Aligned Design, such as the publication by Weng et al. [55], and the IEEE standards released in 2018 [56].

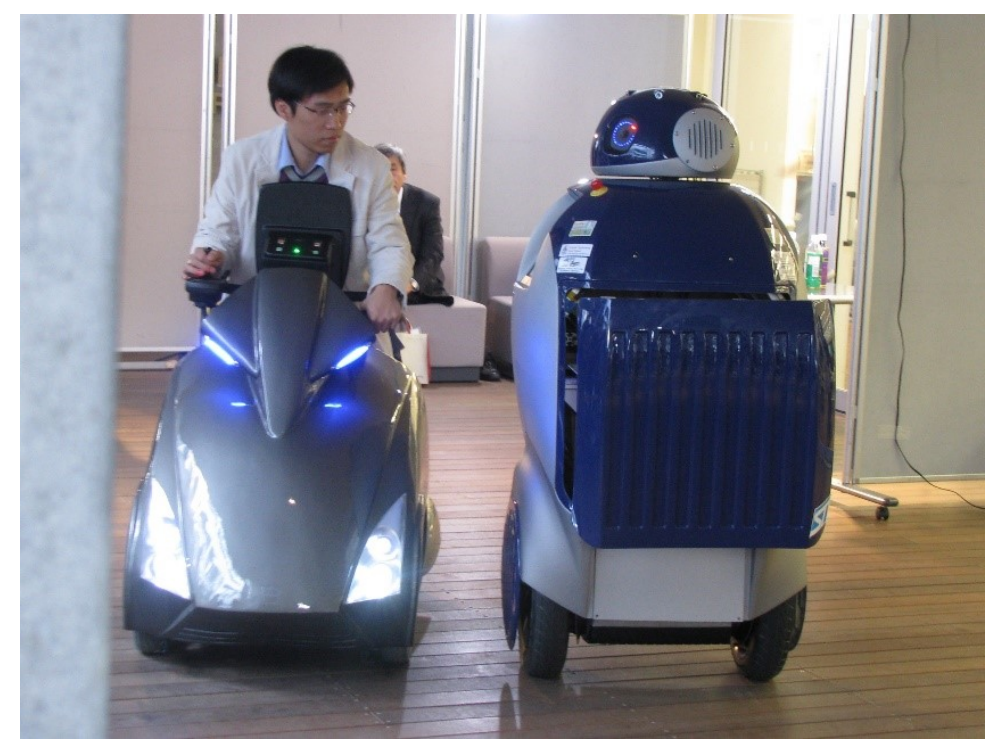


Figure 5: The service robot DustCart (right), displayed at the Italy-Japan Workshop in 2009 together with the Tmsuk RODEM mobility platform (left).

One year after, this theme was faced again, together with its implications at large in modern society and economy, with the 2015 Workshop entitled “Can robots save the world economy?". Here, several talks highlighted that the opportunities given by the rise of robotics may overcome the risks of unemployment. This issue was debated from the viewpoint of both economics and technology, highlighting the challenges and proposing possible solutions for a problem that is still nowadays unsolved. To the threats of job replacement, opportunities also exist as new jobs can be created: the most concrete contribution to this commitment is the realisation of startups. During the event, parallel cases of startups born from robot technologies originated from Sant'Anna and Waseda universities were invited to present themselves and compare their approach. An emblematic example of successful development is EBM Corporation, specialised in robotic technology for cardiac surgery training.

\section{Robotics for sports}

Miniaturised wearable technologies and robotic tools are increasingly populating the field of sports science. Micro electro-mechanical systems (MEMS) are nowadays widespread and allow to finely measure several physical and biophysical parameters of athletes, resulting unobtrusive, in most cases. Italy has a long tradition and top industries (e.g. ST Microelectronics) for MEMS fabrication and is, consequently, also very active in athletes' measurements for assessing and optimising performances [57],[58] Japan is also very active in sports science, in which robotic platforms have played an important role as emulators/trainers for specific sport gestures. Relevant examples are [59] and [60]. At industrial level, in Italy, TechnoGym is at the forefront of this challenge.

Ahead of the 2019 Rugby World Cup and the Tokyo 2020 Olympic games, the field of sport science was gaining increasing exposure in Japan. As such, the 2017 edition of the Italy-Japan Workshop was centred on the topic "Robotics \& Sport Science". In this edition, the multidisciplinary domain of sports science was addressed, by highlighting the potential of robotic technologies to push athletes' performances, but also to promote and maximise a healthy and active lifestyle of the general population, including the elderly. Indeed, in ageing societies such as the Italian and Japanese ones, this may have a profound impact on the quality of life, as sensors and artificial intelligence-based programs can be integrated in wellness products. The discussion fostered in the Workshop showed that robotics is also supporting the deep understanding of some physiological and physical mechanisms in sports (elastic mechanisms in running, respiration, balance, etc.). Robotics was also highlighted as a possible key tool for the future of both elite sports and common healthcare. The 
Workshop also featured a speech by a member of the technology advisory committee of The Tokyo Organising Committee of the Olympic and Paralympic Games 2020, in order to understand the complexity and the social impact of AI in Japan towards the event.

\section{Robotics for arts}

Robotics is a transversal discipline able to break the boundaries between different fields and to draw fully from and to deeply impact branches of knowledge that are even very far from each other.

In 2016, the Workshop theme was "Robotics \& the Arts". Both visual arts (such as painting and sculpture) and performing arts (such as music, fashion, dance and theatre) were covered as fields that can benefit from robotics and find new ways of expression. While artistic production has been an invaluable asset through the centuries in both Italy and Japan, the world of robotics, intertwining with the world of arts, not only can open new fascinating perspectives, but also was stimulated by it. One of the first humanoid robots ever built, in fact, is the pianist robot WABOT-2, developed by Prof. Kato in Waseda in 1984. The event featured a demonstration of the saxophonist robot WAS-4 [61] together with a rock band (Figure 6a). This performance from the Japanese side inspired a repetition one year later in Pisa, Italy (Figure 6b), where the tenor Andrea Bocelli sang with an orchestra conducted by the ABB robot YuMi [62].
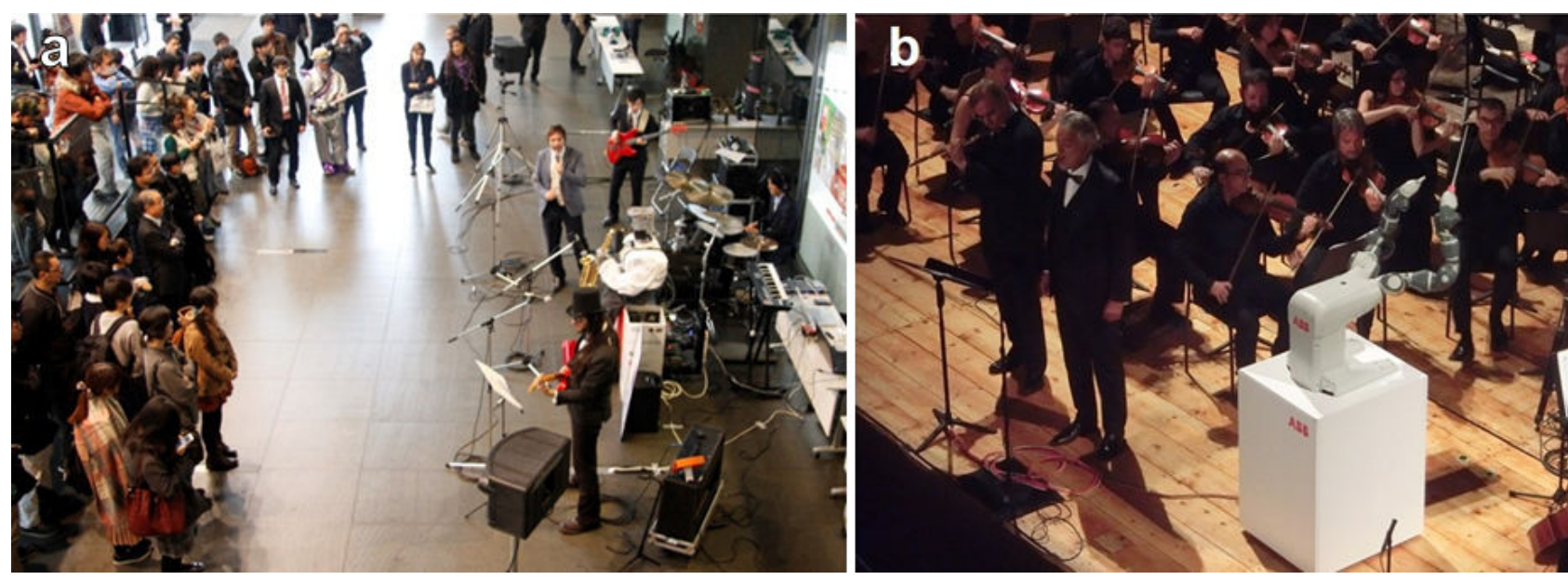

Figure 6: Examples of robots engaged in artistic performances: (a) the Saxophonist robot WAS-4 performing live with a rock band in a hall of Waseda University; (b) Tenor Bocelli with an orchestra conducted by the robot YuMi, at the First International Robotics Festival in Pisa, Italy.

The topic of art was also covered by the 2018 Workshop: anticipating the $500^{\text {th }}$ anniversary of Leonardo da Vinci's death, this event had the title "The First Robots - Leonardo da Vinci and the history and future of mechanisms". It highlighted the influence Leonardo da Vinci had on mechanisms, through the creation of automata; on humanoids morphology, through the Vitruvian 
Man and in general on the birth of science, being yet strongly connected with the world of arts. The android resembling Leonardo da Vinci [63] was one of the most interesting discussion points, following its display at the National Science and Technology Museum in Milan, Italy, during the Expo Milano 2015, and at Grand Front Osaka in Japan. The SanTO robot [15], inspired by Italian neoclassical architecture and sacred art, was also presented, following its first appearance at the sacred art fair Via Pulchritudinis, organised in Rome by the Holy See.

\section{Conclusions}

Italy and Japan are two distant countries that have been historically playing a major role in robotics, and that feature several similar traits and problems. Through the years, the Italy-Japan Workshops explored with a comprehensive perspective compelling issues in robotics, and identified and nurtured emergent research directions with an open-minded, multidisciplinary approach, to the benefit of robotics progress. The different cultural backgrounds of the two countries and the participation of scientists from diverse disciplines, including humanities and social sciences, provided a unique framework to form a new vision of robotics, ultimately leading to new scientific results and new technological developments. We have proposed a collaboration model in which two joint research labs were the key components of the larger strategic objective for the creation and strengthening of a solid link between Japan and Italy. The connection was strongly established by connecting universities, research centres, and small and middle enterprises in the two nations (and, as a natural extension, in Europe and Asia) in the fields of advanced robotics, medical and biomedical technologies and related biomechatronic technologies.

By pursuing this approach at three different levels (excellent research, joint education and strengthening of industrial relationships), the joint Workshops were a key part of the implementation of this vision. The editions run since 2001 highlighted the key issues of Table 1.

Table 1: Summary of lessons learnt and future challenges

\begin{tabular}{|l|l|l|}
\hline Field & Lessons learnt & Future challenges \\
\hline \multirow{2}{*}{ Humanoid robotics } & $\begin{array}{l}\text { The importance of a strict link between } \\
\text { robotics and social science and a joint }\end{array}$ & $\begin{array}{l}\text { Implement simplifying principles } \\
\text { referred to as "simplexity" [64] regarding } \\
\text { development of both disruptive robotics } \\
\text { intention, learning behaviour, and sensing } \\
\end{array}$ \\
\hline
\end{tabular}




\begin{tabular}{|c|c|c|}
\hline & $\begin{array}{l}\text { and legal frameworks in which they could be } \\
\text { effectively implemented. } \\
\text { - Collaboration with end-users is vital for } \\
\text { designing and developing robots with realistic } \\
\text { application opportunities. } \\
\text { - The need to investigate and transfer to robots } \\
\text { the neuroscience models describing brain } \\
\text { mechanisms for perception and action. }\end{array}$ & $\begin{array}{l}\text { collaboration in real-world complex } \\
\text { scenarios }\end{array}$ \\
\hline $\begin{array}{l}\text { Robots for rescue, } \\
\text { exploration and to } \\
\text { face natural disasters }\end{array}$ & $\begin{array}{l}\text { - The awareness that climate change and other } \\
\text { co-factors are making natural disasters } \\
\text { increasingly frequent. } \\
\text { - Robots still have huge margins of } \\
\text { improvement, to match the needs of these } \\
\text { highly "non-structured" applications. } \\
\text { - International collaborations and exchanges } \\
\text { (even possibly extended at the global level) } \\
\text { would dramatically enhance the effectiveness } \\
\text { of research in times of urgent need. }\end{array}$ & $\begin{array}{l}\text { At present, the world is facing the Covid- } \\
19 \text { pandemic. Robotics is expected to to } \\
\text { support disinfection, delivery of } \\
\text { medications and food, measurement of } \\
\text { vital signs, border controls, but also in the } \\
\text { clinical care disease, helping in } \\
\text { prevention, diagnosis and screening, and } \\
\text { patient care and disease management } \\
\text { [65]. }\end{array}$ \\
\hline Biorobotics & $\begin{array}{l}\text { - Rethinking the way robots are designed and } \\
\text { built, including the materials they are made of. } \\
\text { - Understanding that the fields of medical } \\
\text { robotics, bionics and bioinspired technologies } \\
\text { are undergoing a rapid convergence. In 2019, a } \\
\text { new journal was launched (IEEE Transactions } \\
\text { on Medical Robotics and Bionics). Many } \\
\text { Italian and Japanese researchers are now part } \\
\text { of the editorial board [66]. }\end{array}$ & $\begin{array}{l}\text { Miniaturisation of technologies to } \\
\text { provide (possibly non-invasive) therapy } \\
\text { in the target area with the highest } \\
\text { precision and with the smallest side } \\
\text { effects. To this purpose, advanced } \\
\text { materials able to safely interact with the } \\
\text { human tissues and triggering the desired } \\
\text { actions will be needed: materials not only } \\
\text { able to provide structural support and to } \\
\text { guarantee deformability, but also } \\
\text { enabling robot growth, regeneration, } \\
\text { shape change, and biodegradation [67]. }\end{array}$ \\
\hline $\begin{array}{l}\text { Robotics } \\
\text { education }\end{array}$ & $\begin{array}{l}\text { - As stated by Koji Fukuda, the director of The } \\
\text { European Union Institute in Japan, keeping } \\
\text { high level of the education in engineering and } \\
\text { technology is one of the important policies for } \\
\text { the academic institutions. } \\
\text { - Robotics recognised to be one of the key } \\
\text { aspects of education of the new generations. }\end{array}$ & $\begin{array}{l}\text { Set up an education that helps building an } \\
\text { interdisciplinary mindset, which forces } \\
\text { the students to deal with real-life } \\
\text { challenges. }\end{array}$ \\
\hline
\end{tabular}




\begin{tabular}{|c|c|c|}
\hline & $\begin{array}{l}\text { - Practical insights exchanged through } \\
\text { comparing the experiences in educational } \\
\text { robotics in the two countries. }\end{array}$ & \\
\hline $\begin{array}{l}\text { Ethical, legal and } \\
\text { economic aspects of } \\
\text { robotics }\end{array}$ & $\begin{array}{l}\text { - Robotics technologies are part of the progress } \\
\text { of digital technologies and are partly regulated } \\
\text { as such; robot autonomy introduces additional } \\
\text { issues in terms of ethical considerations, } \\
\text { regulations and economic models } \\
\text { - The needed involvement of experts in the } \\
\text { relevant fields. }\end{array}$ & $\begin{array}{l}\text { Multiple solutions and points of view } \\
\text { exist, which may even be poles apart due } \\
\text { to the historical, cultural, religious and } \\
\text { philosophical background of the two } \\
\text { countries; however, Italy-Japan } \\
\text { Worskshops can be a fertile environment } \\
\text { for finding a common ground and } \\
\text { stimulate advancements in the field. }\end{array}$ \\
\hline Robotics for sports & $\begin{array}{l}\text { - Sports are still dominated by semi-qualitative } \\
\text { methodologies, in which coaches and trainers } \\
\text { often rely on their personal impressions rather } \\
\text { than objective and reliable measurements. } \\
\text { There are several margins of application for } \\
\text { robotics in sports. } \\
\text { - Close relationship between the domain of } \\
\text { sports, even at a high competition level (e.g., } \\
\text { elite athletes), and the life quality of ordinary } \\
\text { people. }\end{array}$ & $\begin{array}{l}\text { Demonstrate the real potential of robotics } \\
\text { not only in structured lab environments, } \\
\text { but also in training- and match-based } \\
\text { ones. New technologies may also help } \\
\text { improving amateur athletes and active } \\
\text { elderlies quality of life through } \\
\text { monitoring physiological parameters. }\end{array}$ \\
\hline Robotics for arts & $\begin{array}{l}\text { - The demo sessions gave the idea of the wide } \\
\text { range of applications of automation in the arts. } \\
\text { - Although visual and performing arts are not a } \\
\text { critical field of application of science, the } \\
\text { realisation of automation hides considerable } \\
\text { technical challenges. }\end{array}$ & $\begin{array}{l}\text { Make the advancement of the works } \\
\text { presented in the Workshops and the other } \\
\text { fields of application of robotics mutually } \\
\text { useful in the future. }\end{array}$ \\
\hline
\end{tabular}

While it is not possible to count the exact number of projects, publications and citations that have been directly or indirectly fostered by this connection, we can qualitatively analyse the most prolific field: humanoid robotics, which was at the core of the start of the collaborations. Research in that field has witnessed a continuation of publications (from 2002's prosthetic hand [68] from the Italian side integrated into the humanoids in Japan, all through the development of the "twin" robots WABIAN-2 and SABIAN, up to the studies on facial expressions published in 2014 [69]), with a continuous exchange of personnel (Pisa and Livorno becoming familiar to Japanese researchers, and Waseda University becoming a hub of Italians). This interdisciplinary, inclusive model has valuable 
characteristics that can be exported to different contexts, in other countries, by properly taking into account the peculiarities, the differences and the similarities of the countries involved; however, it is sustainable only through a continuous commitment and a glance to the future challenges.

The latest edition (2019) of the Italy-Japan Workshop was entitled "Robots and the future": here, visionary talks by the participants aimed at fostering the discussion on how robots will be in 20-30 years. The bottlenecks currently hampering the development of very advanced robots were discussed (e.g. actuation, energy, lack of appropriate materials, etc.). Several possible enabling technologies and future paradigm shifts were also proposed and analysed, trying to lay the foundations of a discussion that may inspire the global robotics community. Despite AI plays an increasingly important role in the community, attention was posed instead on the need to revolutionise robot "bodies", delegating to them part of the robot intelligence (the so-called embodied intelligence). Furthermore, there will be the need to unveil the secrets of animal and plant behavior. Nature, in fact, still seems the most powerful source of inspiration for the development of a "science and technology of graceful behaviour", targeting unprecedented robot performance, abilities and impact.

In the future, Italy-Japan Workshops will continue to tackle emergent topics and to provide its contribution to the international intellectual discussion on robotics, on its possible applications domains and on the consequent implications on the society.

\section{Acknowledgements}

We would like to thank the Embassy of Italy in Tokyo for the support received through the last decades. We also acknowledge Salvatore Sessa, Egidio Falotico and Stefano Mazzoleni, for their efforts in the organisation of the events and in pursuing the collaboration between Waseda University and Scuola Superiore Sant'Anna. A final acknowledgment is for all the students and staff involved in the different Workshop editions.

\section{References}

[1] Ceccarelli, M. (2008). Renaissance of machines in Italy: From Brunelleschi to Galilei through Francesco di Giorgio and Leonardo. Mechanism and Machine Theory, 43(12), 1530-1542. https://doi.org/10.1016/j.mechmachtheory.2008.01.001

[2] Yamaguchi, M. (2005). Karakuri: The ludic relationship between man and machine in Tokugawa Japan. In Japan at Play. Routledge.

[3] Source: 2015 List by Our World In Data OWID: https://www.un.org/en/development/desa/population/publications/pdf/fertility/worldFertilityRep ort2015 highlights.pdf 
[4] Source: Statistical Handbook of Japan, Statistics Bureau, https://www.stat.go.jp/english/data/handbook/pdf/2018all.pdf

[5] Takanishi, A. (2019). Historical Perspective of Humanoid Robot Research in Asia. In A. Goswami \& P. Vadakkepat (Eds.), Humanoid Robotics: A Reference (pp. 35-52). https://doi.org/10.1007/978-94-007-6046-2_145

[6] Hashimoto, S., Narita, S., Kasahara, H., Shirai, K., Kobayashi, T., Takanishi, A., et al. (2002). Humanoid Robots in Waseda University-Hadaly-2 and WABIAN. Autonomous Robots, 12(1), 25-38. https://doi.org/10.1023/A:1013202723953

[7] Fukuda, T., Dario, P., \& Yang, G. Z. (2017). Humanoid robotics-History, current state of the art, and challenges. Science Robotics. 2, eaar4043.

[8] Salvini, P., Laschi, C., \& Dario, P. (2010). Design for acceptability: improving robots' coexistence in human society. International Journal of Social Robotics, 2(4), 451-460.

[9] Zecca, M., et al. (2006). From the Human Hand to a Humanoid Hand: Biologically-Inspired Approach for the Development of RoboCasa Hand \#1. In T. Zielińska \& C. Zieliński (Eds.), Romansy 16: Robot Design, Dynamics, and Control (pp. 287-294). Springer.

[10] Takanishi A., Humanoid Robots, and the Culture and History of the Japanese People, Acta Philosophica, vol. 20, no. 1, pp. 29-52, 2011.

[11] Kaplan F., (2004), Who is afraid of the humanoid? Investigating cultural differences in the acceptance of robots, International Journal of Humanoid Robotics, vol. 01, no. 03, pp. 465-480

[12] Bruno B. et al., (2017). Paving the way for culturally competent robots: a position paper, in 26th IEEE International Symposium on Robot and Human Interactive Communication (ROMAN), pp. 553-560.

[13] Trovato G., et al. (2019). Religion and Robots: Towards the Synthesis of Two Extremes. International Journal of Social Robotics 1-18, doi: 10.1007/s12369-019-00553-8.

[14] Trovato G., Kishi T., Kawai M., et al. (2019). The creation of DarumaTO: a social companion robot for Buddhist/Shinto elderlies, in 2019 IEEE/ASME International Conference on Advanced Intelligent Mechatronics (AIM). pp 606-611

[15] Trovato G., et al. (2018). The creation of SanTO: a robot with 'divine' features, in 2018 15th International Conference on Ubiquitous Robots (UR), pp. 437-442

[16] Beira R. et al., (2006). Design of the robot-cub (iCub) head, in Proceedings of 2006 IEEE International Conference on Robotics and Automation, pp. 94-100.

[17] Cheng, J., Chen, X., \& Lukowicz, P. (2015). Towards Coexistence of Human and Robot: How Ubiquitous Computing Can Contribute? In J.-H. Kim, W. Yang, J. Jo, P. Sincak, \& H. Myung 
(Eds.), Robot Intelligence Technology and Applications 3 (pp. 425-431). Springer International Publishing.

[18] Miwa H. et al., (2004). Effective emotional expressions with emotion expression humanoid robot WE-4RII, in 2004 IEEE/RSJ International Conference on Intelligent Robots and Systems, vol. 3, pp. 2203-2208.

[19] Tikhanoff, V., Pattacini, U., Natale, L., \& Metta, G. (2013). Exploring affordances and tool use on the iCub. 2013 13th IEEE-RAS International Conference on Humanoid Robots (Humanoids), 130-137. https://doi.org/10.1109/HUMANOIDS.2013.7029967

[20] ACM-R5H | HiBot. (n.d.). Retrieved September 19, 2019, from http://www.hibot.co.jp/ecommerce/prod-detail/39

[21] Murphy, R. R. (2010). Findings from NSF-JST-NIST Workshop on Rescue Robotics. 2010 IEEE Safety Security and Rescue Robotics, 1-4. https://doi.org/10.1109/SSRR.2010.5981570

[22] Kruijff G.-J. M. et al., "Rescue robots at earthquake-hit Mirandola, Italy: A field report," in 2012 IEEE International Symposium on Safety, Security, and Rescue Robotics (SSRR), College Station, TX, USA, 2012, pp. 1-8.

[23] Guizzo, E., \& Ackerman, E. (2015). The hard lessons of DARPA's robotics challenge. IEEE Spectrum, 52(8), 11-13.

[24] Hashimoto K. et al., (2017). WAREC-1 — A four-limbed robot having high locomotion ability with versatility in locomotion styles, in 2017 IEEE International Symposium on Safety, Security and Rescue Robotics, pp. 172-178.

[25] Negrello, F., et al. (2018). WALK-MAN Humanoid Robot: Field Experiments in a Postearthquake Scenario. IEEE Robotics \& Automation Magazine. 25(3), 8-22.

[26] Dario, P., Guglielmelli, E., Allotta, B., Carrozza, M.C. (1996) Robotics for medical applications. IEEE Robotics \& Automation Magazine. 3(3), 44-56

[27] Taylor, R. H. (2006). A perspective on medical robotics. Proceedings of the IEEE, 94(9), 1652-1664.

[28] Ciuti, G., Valdastri, P., Menciassi, A., \& Dario, P. (2010). Robotic magnetic steering and locomotion of capsule endoscope for diagnostic and surgical endoluminal procedures. Robotica, 28(2), 199-207.

[29] Valdastri, P., Houston, K., Menciassi, A., Dario, P., Sieber, A., Yanagihara, M., \& Fujie, M. Miniaturized cutting tool with triaxial force sensing capabilities for minimally invasive surgery. Journal of Medical Devices. 2007, 1(3): 206-211. 
[30] Harada, K., Bo, Z., Enosawa, S., Chiba, T., \& Fujie, M. G. Bending laser manipulator for intrauterine surgery and viscoelastic model of fetal rat tissue. In Proceedings 2007 IEEE International Conference on Robotics and Automation, 2007, pp. 611-616. IEEE.

[31] Laschi, C., Mazzolai, B., Cianchetti, M. (2016) Soft robotics: technologies and systems pushing the boundaries of robot abilities, Science Robotics, 1(1)

[32] Bao, G., et al. (2018) Soft Robotics: Academic Insights and Perspectives Through Bibliometric Analysis, Soft Robotics, 5(3)

[33] Cianchetti, M., et al. (2014). Soft robotics technologies to address shortcomings in today's minimally invasive surgery: the STIFF-FLOP approach. Soft robotics, 1(2), 122-131.

[34] Runciman, M., Darzi, A., \& Mylonas, G. P. (2019). Soft Robotics in Minimally Invasive Surgery. Soft robotics. Doi: 10.1089/soro.2018.013

[35] Hagiwara, M., et al. (2011). On-chip magnetically actuated robot with ultrasonic vibration for single cell manipulations. Lab on a Chip, 11(12), 2049-2054.

[36] Ricotti, L., et al. (2017). Biohybrid actuators for robotics: A review of devices actuated by living cells. Science Robotics, 2(12), eaaq0495.

[37] Fujie, T., Ricotti, L., Desii, A., Menciassi, A., Dario, P., \& Mattoli, V. Evaluation of substrata effect on cell adhesion properties using freestanding poly (l-lactic acid) nanosheets. Langmuir, 2011, 27(21), 13173-13182.

[38] Ricotti, L., \& Fujie, T. (2017). Thin polymeric films for building biohybrid microrobots. Bioinspiration \& Biomimetics, 12(2), 021001.

[39] Kainuma, S., et al. (2015). In Vivo Assessment of Novel Stentless Valve in the Mitral Position. Circulation Journal, 79(3), 553-559.

[40] Iacovacci, V., Ricotti, L., Dario, P., \& Menciassi, A. (2014). Design and development of a mechatronic system for noninvasive refilling of implantable artificial pancreas. IEEE/ASME Transactions on Mechatronics, 20(3), 1160-1169.

[41] Catapano, G., \& Buscaroli, A. (2017). Renal function replacement by hemodialysis: fortyyear anniversary and a glimpse into the future at hand. The International journal of artificial organs, 40(7), 313-322.

[42] https://www.jst.go.jp/impact/bionichumanoids/en/index.html

[43] Barker, B. S., \& Ansorge, J. (2007). Robotics as means to increase achievement scores in an informal learning environment. Journal of Research on Technology in Education, 39(3), 229243. https://doi.org/10.1080/15391523.2007.10782481

[44] Papert, S. (1980). Mindstorms: Children, Computers, and Powerful Ideas. New York, NY, USA: Basic Books, Inc. 
[45] Grzybowski, M. (2013). Educational Technologies in South Korea. General and Professional Education, 3-9.

[46] Penaloza, C. I., Lucho, C., \& Cuellar, F. (2015). Towards the Design of Robots Inspired in Ancient Cultures as Educational Tools. CR@RO-MAN. https://doi.org/10.1007/978-3-31942945-8_7

[47] Bilotta, E., Gabriele, L., Servidio, R., \& Tavernise, A. (2009). Edutainment Robotics as Learning Tool. In Z. Pan, A. D. Cheok, W. Müller, \& M. Chang (Eds.), Transactions on Edutainment III (pp. 25-35). https://doi.org/10.1007/978-3-642-11245-4 3

[48] Di Lieto, et al. (2020) Empowering Executive Functions in 5- and 6-Year-Old Typically Developing Children Through Educational Robotics: An RCT Study. Frontiers in psychology, $10: 3084$

[49] Castro, E., et al. (2019) Educational Robotics and empowerment of executive cognitive processes: from typical development to special educational needs, Form@re - Open Journal Per La Formazione in Rete, 19(1), 60-77

[50] Veruggio, G. (2005). The Birth of Roboethics. In J. Doe (Ed.), ICRA 2005, IEEE International Conference on Robotics and Automation, Workshop on Roboethics (pp. 1-4).

[51] Tzafestas, S. G. (2018). Roboethics: Fundamental Concepts and Future Prospects. Information, 9(6), 148. https://doi.org/10.3390/info9060148

[52] World Robot Declaration. (n.d.). Retrieved September 19, 2019, from http://prw.kyodonews.jp/prwfile/prdata/0370/release/200402259634/index.html

[53] Salvini P., Laschi C., and Dario P., “Do Service Robots Need a Driving License? [Industrial Activities]," IEEE Robotics \& Automation Magazine, vol. 18, no. 2, pp. 12-13, Jun. 2011.

[54] Palmerini E., Bertolini A., Battaglia F., Koops B.-J., Carnevale A., and Salvini P., "RoboLaw: Towards a European framework for robotics regulation," Robotics and Autonomous Systems, vol. 86, pp. 78-85, Dec. 2016.

[55] Weng, Y., \& Hirata, Y. (2018). Ethically Aligned Design for Assistive Robotics. 2018 IEEE International Conference on Intelligence and Safety for Robotics (ISR), 286-290. https://doi.org/10.1109/IISR.2018.8535889

[56] IEEE Standards Association. (2018). Ethically Aligned Design, Version 2 (EADv2). Retrieved from https://ethicsinaction.iee.org/

[57] Ciuti, G., Ricotti, L., Menciassi, A., \& Dario, P. (2015). MEMS sensor technologies for human centred applications in healthcare, physical activities, safety and environmental sensing: a review on research activities in Italy. Sensors, 15(3), 6441-6468. 
[58] Ricotti, L., Rigosa, J., Niosi, A. and Menciassi, A., (2013). Analysis of balance, rapidity, force and reaction times of soccer players at different levels of competition. PloS one, 8(10), p.e77264.

[59] Toyama, S., et al. (2017). Self-Coaching of Forearm Pass with Humanoid Robot. In Proceedings of the Companion of the 2017 ACM/IEEE International Conference on HumanRobot Interaction (pp. 303-304).

[60] Yamada, K. (2017). Robot Table Tennis Tutor as an Example of "Harmony between Human and Robot" (Japanese Title: 卓球ラリーロボット). Journal of the Institute of Electrical Engineers of Japan, 137(2):81-84, DOI: 10.1541/ieejjournal.137.81

[61] Xia G. et al., "Expressive Humanoid Robot for Automatic Accompaniment," in Proceedings of the Sound and Music Computing Conference 2016, Hamburg, Germany, 2016.

[62] "YuMi taking the stage." [Online]. Available: https://new.abb.com/news/detail/2069/yumitaking-the-stage. [Accessed: 16-Feb-2019].

[63] "Leonardo da Vinci comes back as an android - ResOU." [Online]. Available: https://resou.osaka-u.ac.jp/en/research/2015/20150821_1. [Accessed: 16-Feb-2019].

[64] Falotico, E., Berthoz, A., Dario, P., \& Laschi, C. (2017). Sense of movement: Simplifying principles for humanoid robots. Science Robotics, 2(13), eaaq0882.

[65] Yang, G. Z. et al. (2020). Combating COVID-19-The role of robotics in managing public health and infectious diseases. Science Robotics. 5(40), eabb5589

[66] Dario, P. (2019). Editorial Medical Robotics and Bionics: A New Interdisciplinary Adventure. IEEE Transactions on Medical Robotics and Bionics, 1(1), 1-3.

[67] Mazzolai, B., \& Laschi, C. (2020). A vision for future bioinspired and biohybrid robots. Science robotics, 5(38), eaba6893.

[68] Carrozza M.C. et al, "The development of a novel prosthetic hand-ongoing research and preliminary results", IEEE/ASME Transactions on Mechatronics 7 (2), 108 - 114, 2002

[69] Kishi T. et al, "Development of a comic mark based expressive robotic head adapted to Japanese cultural background", 2014 IEEE/RSJ International Conference on Intelligent Robots and Systems, Chicago, USA, 2014 